\title{
Experimental model of gastroesophageal reflux in rats $^{1}$
}

\author{
Modelo experimental de refluxo gastroesofágico em ratos
}

\author{
Edmilson Vieira Gaia Filho², Alberto Goldenberg ${ }^{3}$, Henrique Oliveira Costa ${ }^{4}$
}

1. Study conducted at Escola de Ciências Médicas de Alagoas [School of Medical Sciences], UNCISAL, and in the Postgraduate Program in Surgical Gastroenterology, Federal University of São Paulo (UNIFESP), Brazil.

2. Assistant Professor, Discipline of Basis of Surgical Technique and Anesthesiology, Escola de Ciências Médicas de Alagoas -UNCISAL.

3. PhD and Associate Professor, Discipline of Surgical Gastroenterology, Postgraduate Program, UNIFESP.

4. Associate Professor, Discipline of Pathological Anatomy, Escola de Ciências Médicas de Alagoas - UNCISAL.

\begin{abstract}
Purpose: To develop an experimental model of gastroesophageal reflux in rats. Methods: Sixty Wistar rats underwent surgery and were assigned to one of the three groups of twenty animals each. The animals in group A underwent total esophageal myectomy and, in group (B), underwent partial myectomy. The third group was the control group (C). A contrast radiographic study of the esophagus was performed to evaluate gastroesophageal reflux. The anatomopathological study of the esophagus was used to evaluate esophagitis. Results: During the 30-day postoperative follow-up, 14 animals in group A presented with reflux of barium in the esophagus. The presence of barium in the esophagus was observed in 7 animals in group B and in 2 animals in the control group. The result of the histopathology examination was controversial. A marked weight loss in the rats undergoing total myectomy was observed, however there was no significant statistical difference. Conclusion: Total myectomy in the lower third of the esophagus caused gastroesophageal reflux in the majority of the animals.
\end{abstract}

Key words: Gastroesophageal Reflux. Esophagitis, Peptic. Animal Experimentation.

\section{RESUMO}

Objetivo: Desenvolver um modelo experimental de refluxo gastroesofágico em ratos. Métodos: Sessenta ratos, Wistar, foram operados e distribuídos em três grupos de vinte animais. Os animais foram submetidos a miectomia total do esôfago em um grupo(A), e em outro grupo foram submetidos a miectomia parcial(B). O terceiro grupo foi o grupo controle(C). Para avaliar o refluxo gastroesofágico realizou-se o estudo radiológico contrastado do esôfago. O estudo anátomo-patológico do esôfago foi utilizado para avaliar esofagite. Resultados: Durante os 30 dias de pósoperatório, 14 animais do grupo A apresentaram refluxo de Bário no esôfago. Em 07 animais do grupo B e em 02 do grupo controle, foram observados a presença de Bário no esôfago. O resultado do histopatológico foi controverso. Observou-se perda ponderal importante nos ratos submetidos a miectomia total, porém não existiu diferença estatística. Conclusão: A miectomia total realizada no terço inferior do esôfago provocou refluxo gastroesofágico na maioria dos animais.

Descritores: Refluxo Gastroesofágico. Esofagite Péptica. Experimentação Animal.

\section{Introduction}

The gastroesophageal reflux disease (GERD) has gained clinical and surgical importance over the past decade. It is one of the most common complaints in medical offices, affecting approximately $10 \%$ of the population ${ }^{1}$. It accounts for $75 \%$ of esophageal diseases ${ }^{2,3}$. The treatment of GERD is still controversial. Experimental models of GERD are important to study the action of the acid and alkaline juices, as well as to evaluate the therapeutic efficacy of drugs and surgical techniques. The closure of the pylorus and of the rumen helped studying reflux esophagitis in rats, according to the models developed ${ }^{4,5,6}$. The authors also tested the therapeutic efficacy of different esophageal mucosa protective drugs. The rat's stomach comprises two anatomical parts: the upper part is composed of the rumen (cardiac region, pro-ventricle), which is equivalent to the gastric fundus and greater curvature in humans. It works exclusively as a reservoir. The epithelium is thin and similar to that of the esophagus, and can be easily identified by its transparent aspect. The lower part is known as the pyloric or glandular region ${ }^{7}$. In the human stomach, it would be located in the regions of the lesser curvature, body and antrum. The rat esophagus is composed of a muscle layer lining the mucosal layer of the organ. The muscle layer is formed by striated muscle. The muscle layer of the mucosa is well developed. The mucosa epithelium is of the stratified squamous type. The abdominal portion of the esophagus is redundant and easily approached via laparotomy. The cardia functions as an efficient barrier against GER ${ }^{7}$. Crema ${ }^{8}$ developed a reflux esophagitis model in dogs, in Brazil. This author performed an extensive cardiomyotomy and 
compared it with three types of fundoplication (anterior, posterior and lateral). The objective was to conduct a comparative study with the technical modifications of different anti-reflux valves. Despite the existence of various experimental models of gastroesophageal reflux (GER), there is no consensus on the ideal model. The study, developed by $\mathrm{Crema}^{8}$ in dogs, is the one that comes closest to the functional changes leading to reflux in humans. No similar studies were found in small size animals; therefore this study proposes to develop a new, less complex model in rats, using a surgical technique able to preserve the original anatomy of the organs involved.

\section{Purpose}

To develop an experimental model of gastroesophageal reflux in rats.

\section{Methods \\ Sample}

Sixty Wistar male rats with weight ranging from 222.5 to 397 grams, and age between 6 and 8 months originating in the ECMAL-UNCISAL vivarium were used. They were fed with standard feed and 5\% glucose solution. Surgical procedures followed the criteria, technical standards and international rights applied to animal research. The study was approved by the Research Ethics Committee of ECMAL-UNCISAL and UNIFESP-EPM.

\section{Assignment of the animals in three groups \\ Group A - 20 animals. Total myectomy. \\ Group B - 20 animals. Partial myectomy. \\ Group C (Control) - 20 animals. \\ Preoperative preparation and anesthesia}

The animals were fastened for 2 hours prior to surgery. Intraperitoneal anesthesia with $20 \mathrm{mg} / \mathrm{ml}$ xylazine chloride, and $100 \mathrm{mg} / \mathrm{ml}$ ketamine chloride, $1: 1$ at $0.1 \mathrm{ml}$ of the solution for each $100 \mathrm{~g}$ weight was performed. Following hair removal of the abdominal region, the skin was cleansed with $10 \%$ polyvinylpyrrolidone-iodine (PVPI).

\section{Surgical technique}

The animals underwent a 3-cm midline laparotomy starting at the xiphoid process. The peritoneal cavity was inspected. The animals were numbered from 1 to 60 . At this point, each animal was raffled to be assigned to one of the study groups, this being our randomization criteria. In group A animals, the muscle layer involving the abdominal esophagus was resected (myectomy) via a $1.5 \mathrm{~cm}$ anterior myotomy starting at the gastroesophageal junction (GEJ) (Figures 1, 2 and 3). The muscle layer was sent to histology examination. In group $B$, we resected a $1.5 \mathrm{~cm}$-longx $2 \mathrm{~mm}$ wide strip of the anterior muscle layer of the abdominal esophagus, starting from the GEJ. The muscle layer was also sent to histology examination (Figure 4).

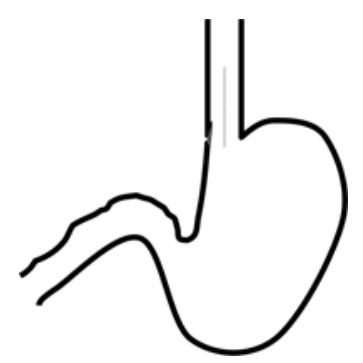

FIGURE 1 - Drawing of the anterior myotomy in the esophagus.

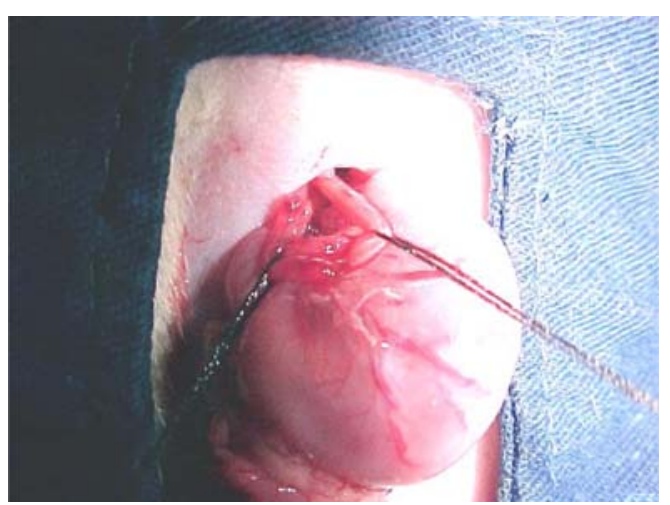

FIGURE 2 - Photo of rat n.7, group A. Dissection and separation of the muscle layer (left) from the esophagus (right).

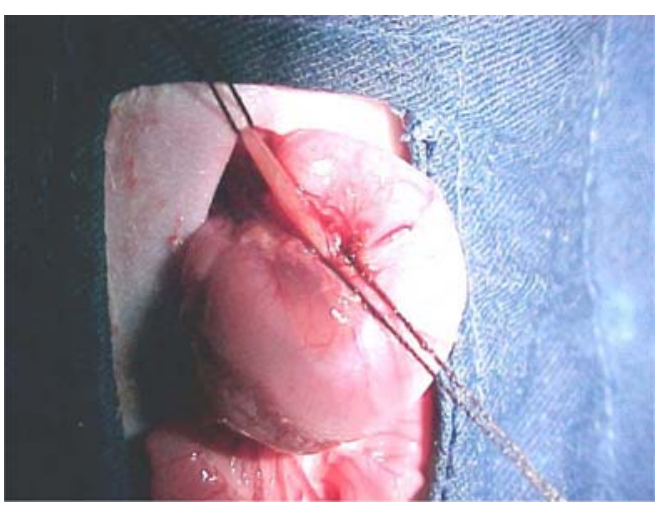

FIGURE 3 - Photo of rat n.7, group A. Lower esophagus without the muscle layer.

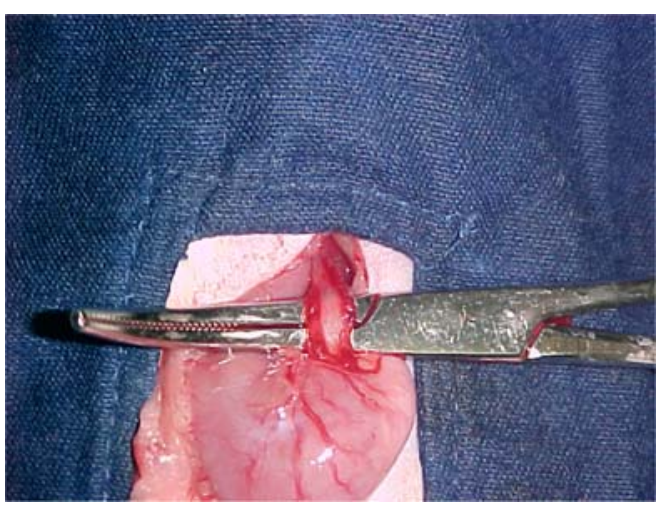

FIGURE 4 - Photo of rat n.25, group B. Removal of a longitudinal strip of the anterior muscle layer of the lower esophagus. 
In group $\mathrm{C}$, the procedure was restricted to esophagus palpation. A mononylon 3-0 suture in a continuous pattern was performed on the aponeurosis of the rectus abdominis muscles. The skin was sutured in a similar manner. The animals presenting with perforation and/or hemorrhage of the esophagus, stomach, and/or duodenum were excluded.

\section{Postoperative care}

Following the surgical procedure, the animals were allowed to recover from anesthesia in individual cages, and were then fed on a liquid diet. As of the eighth day, the animals were advanced to a regular diet. Oral dipyrone (drops) was given from the immediate postoperative period to the seventh postoperative day, at a dose of 1 drop/250g/ day. The animals were observed for alterations in esophageal motility, such as regurgitation. The animals were observed daily in the vivarium for 30 days, under the supervision of the veterinarian in charge.

\section{Second procedure \\ Evaluation of the gastroesophageal reflux}

After 30 days, the animals underwent a second procedure, following the same sequence of fasting, anesthesia, weight measurement, and exposure of the peritoneal cavity, according to the previous description.

\section{Radiographic study}

An 8-Fr Nelaton catheter was inserted through a $2 \mathrm{~mm}$ transversal duodenotomy $3 \mathrm{~cm}$ from the pylorus. The proximal tip of the catheter was placed next to the pylorus. A 0-cotton suture was placed around the duodenum close to the pylorus with the purpose of closing the duodenum and fixing the Nelaton catheter. A second fixation was performed $3 \mathrm{~cm}$ away (Figure 5). Barium contrast was administered via the catheter. The contrast was injected by gravity using a $45-\mathrm{cm}$ liquid column. A $10-\mathrm{ml}$ syringe containing $4 \mathrm{ml}$ of barium solution and $4 \mathrm{ml}$ of saline solution was connected to the Nelaton catheter. The distal tip of the catheter was placed vertically $45 \mathrm{~cm}$ away from the animal. This solution was injected in the animal's stomach by spontaneous and gravitational drip (Figures 6 and 7). Four $\mathrm{ml}$ of the solution were injected. Radiographies were taken according to the sequence of the contrast injected $(1.5 \mathrm{~m}$, $2 \mathrm{ml}, 3 \mathrm{ml}$, and $4 \mathrm{ml}$ ). The radiographs were analyzed by two independent radiologists for the presence or absence of barium in the esophagus, and, if present, for the region in the esophagus where barium was detected.

\section{Anatomopathological study}

The esophagus was resected over a styrofoam board, and gross examination was performed. The specimen was examined for esophagitis according to the following histopathological criteria: elongation of the papilla, hyperkeratosis, hypergranulosis, eosinophils in the GEJ, vascular congestion, neovascular formation, atrophy of the muscle layer of the mucosa, and exocytosis.

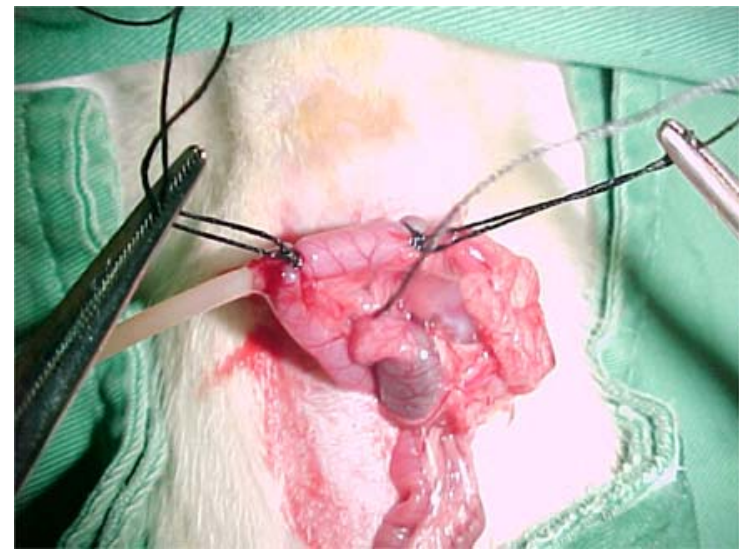

FIGURE 5 - Photo of rat n.58, group C. Reoperation. Fixation of the catheter to the duodenum (proximal and distal).

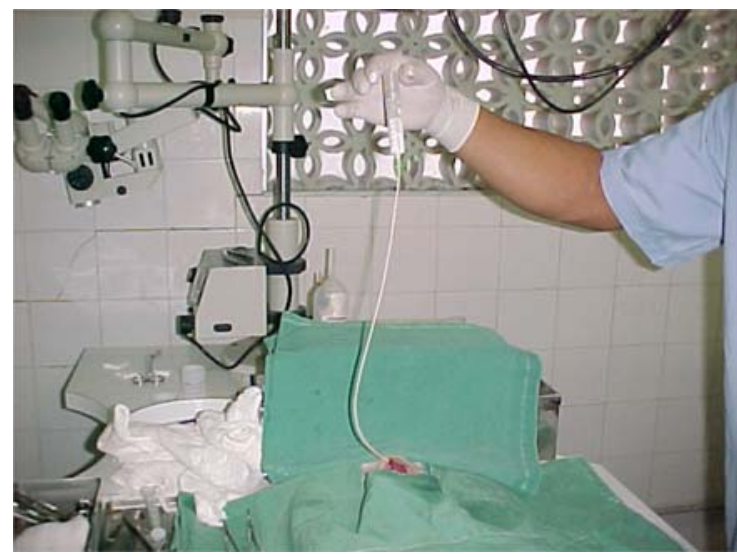

FIGURE 6 - Photo of rat n.14, group A. Barium instillation.

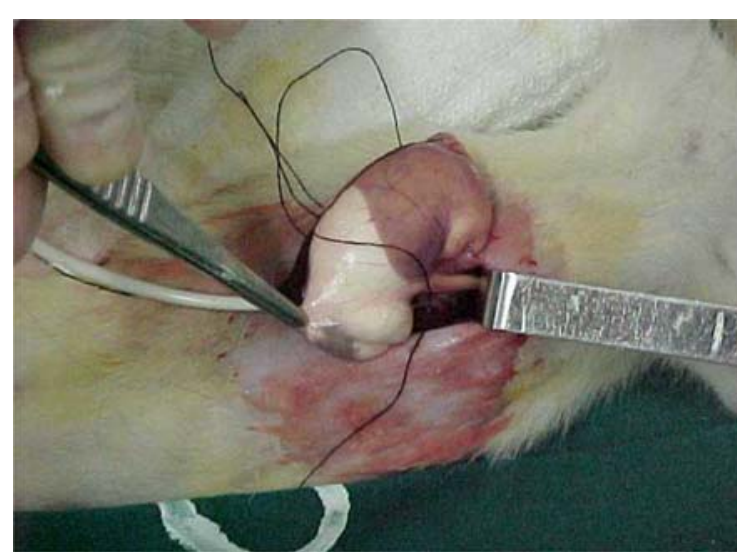

FIGURE 7 - Photo of rat n.14, group A. Reoperation. Presence of barium in the stomach and esophagus (without muscle layer). Rat's anatomy.

\section{Statistical planning}

The Student's $t$ test was used for the analysis of variance between the groups. The confidence interval calculated was $95 \%$, with a 5\% significance level. An alpha (á) value equal to 0.05 was used to reject the null hypothesis. 


\section{Results}

\section{Postoperative course}

The procedures proposed were adequately performed. Six deaths occurred in the late postoperative follow-up (postoperative weeks 2 and 3) among the animals undergoing total myectomy. These cases were excluded from the study because they did not complete a 30-day follow-up. Autopsy could be performed in one of these animals. With this procedure, fibers from the feed were identified inside the alveoli.

\section{Weight loss evaluation}

The weight of the animals ranged from $222.5 \mathrm{~g}$ to $397 \mathrm{~g}$ prior to the first surgery. The results are shown in Tables 1 , 2, 3, 4 and 5. The level of freedom (lf) was 38. The statistical test $(t)$ value was 0.18 in the comparison between groups $A$ and B. Between groups A and C, $t$ value was 0.19 , and between groups $\mathrm{B}$ and $\mathrm{C}$ it was -0.05 . Based on the critical interval between -1.68 and +1.68 , we can state that there was no difference in weight between the three groups, because $t$ corresponded to this interval.

TABLE 1 - Weight (in grams) of group A rats prior to the first and second surgeries.

\begin{tabular}{lcc}
\hline Discrimination & $\begin{array}{c}\text { Prior to } \\
1^{\text {st }} \text { surgery }\end{array}$ & $\begin{array}{c}\text { Prior to } \\
2^{\text {nd }} \text { surgery }\end{array}$ \\
\hline Mean & 293.5 & 266.8 \\
Standard deviation & 31.3 & 45.2 \\
Maximum weight & 362.5 & 358.5 \\
Minimum weight & 222.5 & 196.5 \\
\hline
\end{tabular}

TABLE 2 - Weight (in grams) of group B rats prior to the first and second surgeries.

\begin{tabular}{lcc}
\hline Discrimination & $\begin{array}{c}\text { Prior to } \\
\text { 1st surgery }\end{array}$ & $\begin{array}{c}\text { Prior to } \\
\text { 2nd surgery }\end{array}$ \\
\hline Mean & 277.6 & 296.6 \\
Standard deviation & 23.0 & 23,1 \\
Maximum weight & 311.0 & 339.9 \\
Minimum weight & 229.5 & 249.8 \\
\hline
\end{tabular}

TABLE 3 - Weight (in grams) of group C rats prior to the first and second surgeries.

\begin{tabular}{lcc}
\hline Discrimination & $\begin{array}{c}\text { Prior to } \\
\text { 1st surgery }\end{array}$ & $\begin{array}{c}\text { Prior to } \\
\text { 2nd surgery }\end{array}$ \\
\hline Mean & 283.9 & 305.2 \\
Standard deviation & 44.5 & 42.0 \\
Maximum weight & 397.0 & 412.5 \\
Minimum weight & 235.0 & 252.0 \\
\hline
\end{tabular}

TABLE 4 - Weight (in grams) of the rats prior to the second surgery.

\begin{tabular}{lccc}
\hline & \multicolumn{3}{c}{ Groups } \\
\cline { 2 - 4 } Discrimination & A & B & C \\
\hline Mean & 266.8 & 296.6 & 305.2 \\
Standard deviation & 45.2 & 23.1 & 42.0 \\
\hline
\end{tabular}

TABLE 5 - Weight loss of the rats

\begin{tabular}{ccc}
\hline Groups & Weight Loss & No Weight Loss \\
\hline A & $16(0.800)$ & $04(0.200)$ \\
B & $03(0.150)$ & $17(0.850)$ \\
C & $02(0.100)$ & $18(0.900)$ \\
\hline
\end{tabular}

\section{Radiographic study}

Results are shown in table 6 and documented in Figures 8 and 9 . Based on these data, we can state that the probability of occurring reflux with the surgical technique used in group A was significantly higher than with the procedure performed in groups B and C. We observed that esophageal reflux did not predominate in group B when compared with group C.

TABLE 6 - Evaluation of gastroesophageal reflux by the presence of barium in the esophagus.

\begin{tabular}{llll}
\hline Groups & $\begin{array}{l}\text { Presence of } \\
\text { barium in the } \\
\text { esophagus }\end{array}$ & $\begin{array}{l}\text { Absence of barium } \\
\text { in the esophagus }\end{array}$ & Total \\
\hline Group A & 4 rats $(0.700)$ & 06 rats $(0.300)$ & 20 rats \\
Group B & 07 rats $(0.350)$ & 13 rats $(0.650)$ & 20 rats \\
Group C & 02 rats $(0.100)$ & 18 rats $(0.900)$ & 20 rats \\
\hline
\end{tabular}

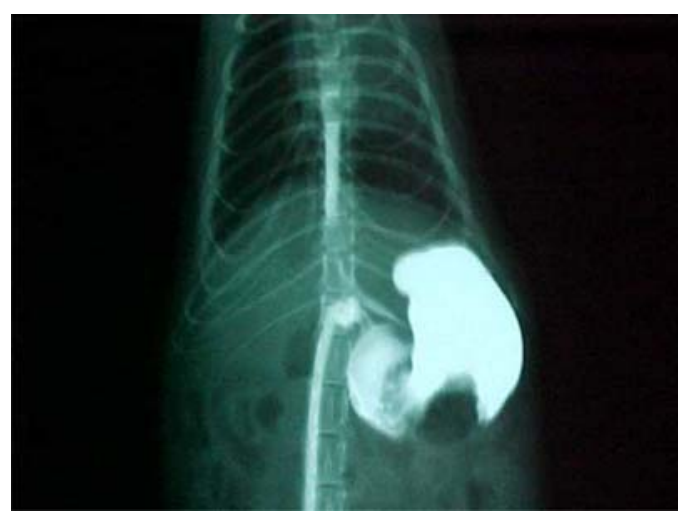

FIGURE 8 - Photo of rat n.9, group A. Radiography showing the presence of barium in the esophagus, following instillation of $4 \mathrm{ml}$ of contrast.

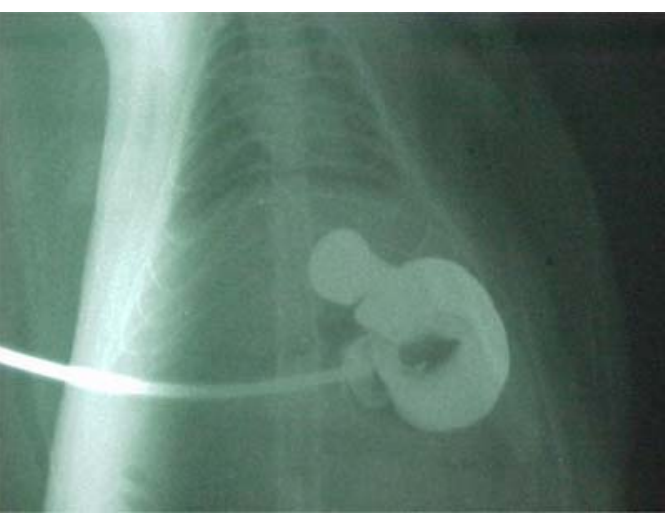

FIGURE 9 - Photo of rat n.41, group C. Contrast-enhanced radiography. Absence of barium in the esophagus, following instillation of $4 \mathrm{ml}$ of contrast. 


\section{Anatomopathological study}

Animals in groups A and B presented with adherences involving the liver and the esophagus. No gross changes were observed in the esophageal mucosa. The histological study of the muscle layer of the esophagus in animals of groups A and B confirmed the presence of muscle tissue. The presence of nerve bundles was observed in the muscle layer. Results are shown in Table 7 and documented in Figures 10,11, 12, 13 and 14. The statistical analysis did not reveal differences between groups.

TABLE 7 - Histological changes observed on day 30 in the esophagus of the animals, in groups A, B, and C.

\begin{tabular}{llll}
\hline Histological changes & \multicolumn{1}{c}{ A } & \multicolumn{1}{c}{ B } & \multicolumn{1}{c}{ C } \\
\hline Elongation of the papilla & $20(100 \%)$ & $20(100 \%)$ & $20(100 \%)$ \\
Hyperkeratosis & $20(100 \%)$ & $20(100 \%)$ & $20(100 \%)$ \\
Hypergranulosis & $20(100 \%)$ & $20(100 \%)$ & $20(100 \%)$ \\
Eosinophils in GEJ & $18(90 \%)$ & $18(90 \%)$ & $19(95 \%)$ \\
$\begin{array}{l}\text { Vascular congestion } \\
\text { Neovascular formation }\end{array}$ & $14(70 \%)$ & $5(25 \%)$ & $14(70 \%)$ \\
$\begin{array}{l}\text { Atrophy of the muscle } \\
\text { layer of the mucosa }\end{array}$ & $11(55 \%)$ & $5(25 \%)$ & $5(25 \%)$ \\
Exocytosis & $6(30 \%)$ & $12(60 \%)$ & $7(35 \%)$ \\
\hline
\end{tabular}

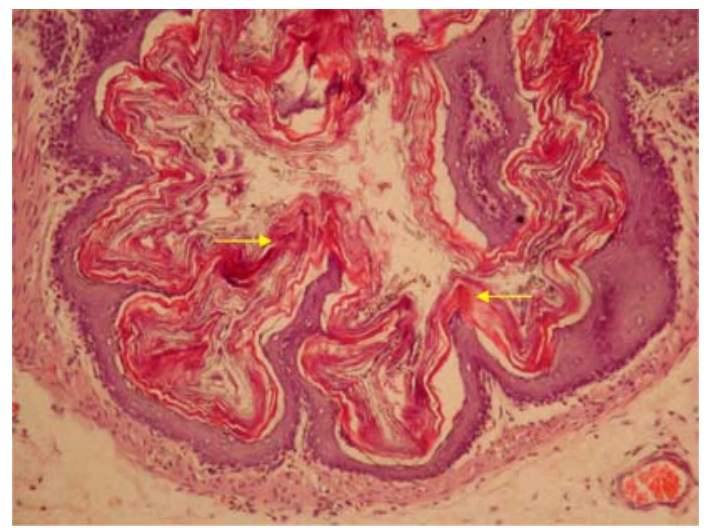

FIGURE 10 - Photomicrography of rat n.8, group A. Histological study of the esophagus stained with Hematoxylin-Eosin(HE). Presence of severe hyperkeratosis (arrows). 5x.

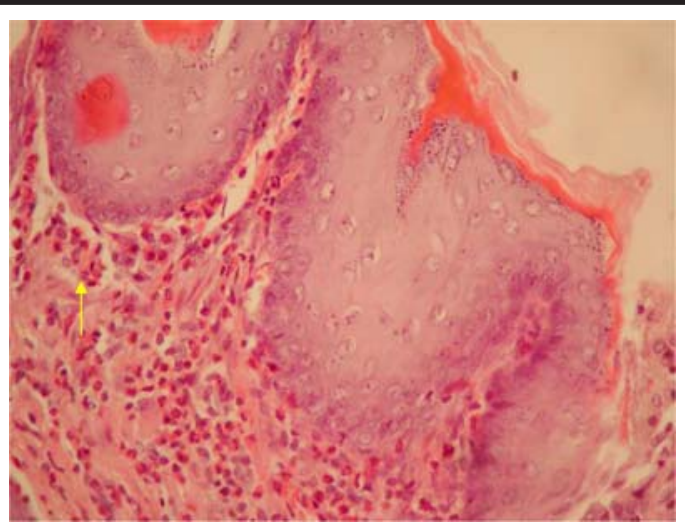

FIGURE 11 - Photomicrography of rat n.10, group A. Histological study of the esophagus. Presence of eosinophils (arrow). HE staining. 40x.

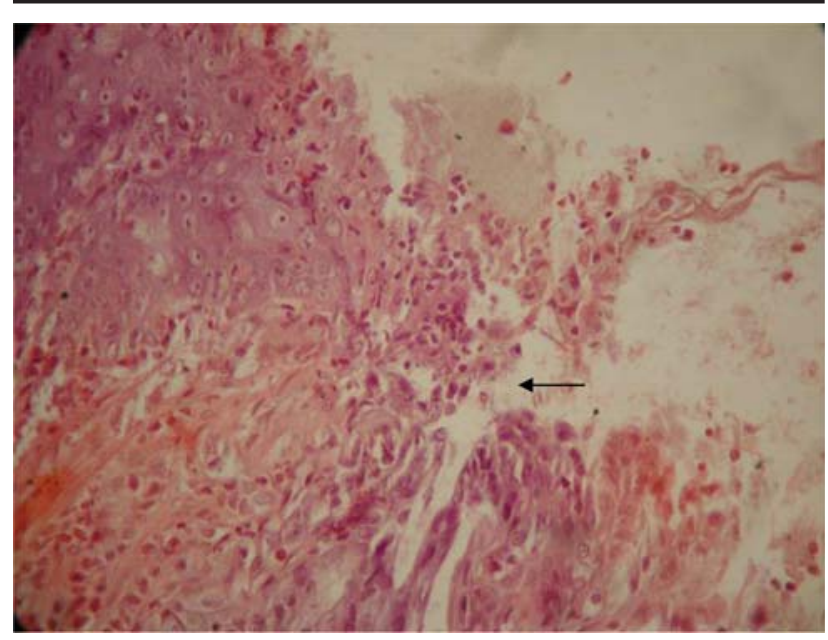

FIGURE 12 - Photomicrography of rat n.20, group A. Histological study of the esophagus. Presence of erosion (arrow). HE staining. 40x.

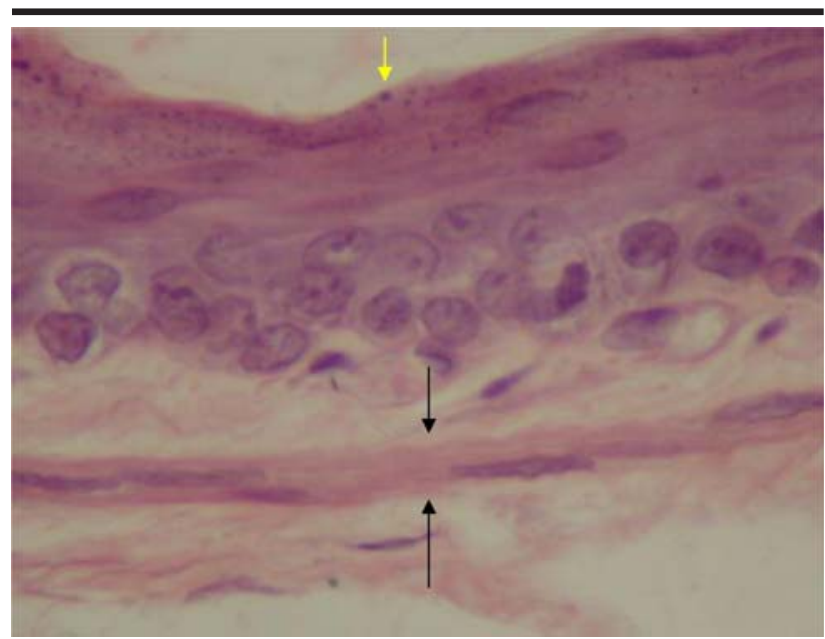

FIGURE 13 - Photomicrography of rat n.16, group A. Histological study of the esophagus stained with HE. Presence of hypergranulosis (yellow arrow). Focal atrophy (black arrows) in the muscle layer of the mucosa. 40x.

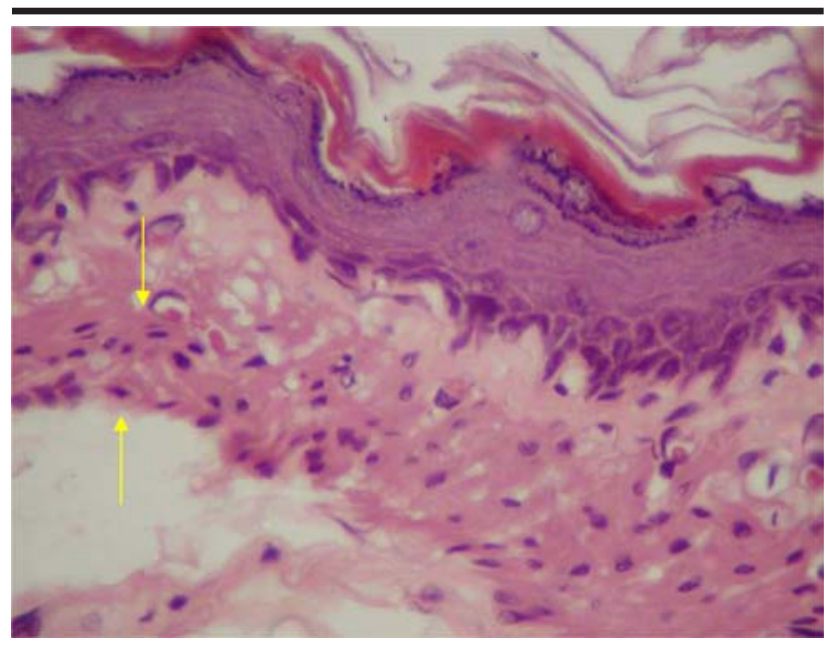

FIGURE 14 - Photomicrography of rat n.48, group C. Histological study of the esophagus stained with HE. Normal muscle layer of the mucosa (arrows). 10x. 


\section{Discussion}

An experimental model in rats evaluated with radiographic and histological studies of the esophagus was developed with the objective of investigating the occurrence of gastroesophageal reflux. The choice of rats enabled the use of a larger sample, since rats are small animals. The breeding and maintenance of these animals are easy, as well as the performance of procedures in them. Costs and surgical time are smaller when compared with those spent with large size animals. To obtain a uniform sample, rats of the same species and sex and with approximately the same weight and age were used. Prophylactic antibiotics were not used in the present model because of the low probability of occurrence of infections. The site to be approached was considered clean and the surgical time short. Antibiotics were used in a study carried out by Salmon and Hem, ${ }^{9}$ Kobori and Seto ${ }^{11}$. Postponing the introduction of a solid diet was related to a higher mortality in the group of animals undergoing total myectomy, in the pilot project phase. The animals in this group regurgitated the feed frequently. In the present experimental study, total (including the vagus nerve) and partial (preserving the vagus) myectomy was performed in the abdominal esophagus of rats, with the objective of developing an experimental model of GER in small size animals, preserving the anatomy of the organs involved. No technical difficulties were found during the performance of total and partial myectomy. In group A animals, the pylorus was denervated because of truncal vagotomy during total myectomy. A significant gastric dilation occurred, with the presence of a large amount of feed residues during reoperation. This could be secondary to delayed gastric emptying caused by vagotomy. The advantage of this model is that it enables future use of new anti-reflux surgical techniques, as well as the administration of new therapeutic drugs. Other advantages of the model developed in this experiment are: shorter anesthesia time, enabling early recovery of the animals; absence of anastomoses in the digestive system; lower morbidity and mortality, enabling a better use of the animal and avoiding delays in the investigation; it can be performed in University Centers, where state-of-the-art technology is not available. In models developed by anatomical changes occurred because of anastomoses performed in the digestive system. The models published by these authors were not able to reproduce, in small size animals, the GER exclusively related to nonfunction of the cardia, as occurs in humans ${ }^{7,9,10,12,13,14,15,16}$. These authors' studies were not applicable to evaluate the therapeutic efficacy of drugs aimed at reducing gastric acidity and GER in animals previously gastrectomized. The present experiment sought to evaluate the importance of the destruction of the GEJ and of the lower third of the esophagus as a cause of GER, using total and partial myectomy. Studies ${ }^{8,17}$ collaborated with the present experiment for developing reflux esophagitis models in female monkeys and dogs, respectively, through cardiomyotomy. On the other hand, Smiddy and Atkinson ${ }^{18}$ performed cardiomyotomy in dogs and concluded that myotomy did not facilitate reflux in the cardia. Esophagitisinducing drugs were not used in the present experimental model. This study tried to cause esophagitis by interfering with one of the barriers against gastroesophageal reflux, with the objective of simulating pathophysiological changes, such as those occurring in humans. Kobori and Seto $^{11}$ developed a reflux model using total gastrectomy and esophagojejunal anastomosis, adding the ingestion of hydrochloric acid. The disadvantages of this study in relation to the present experiment are the use of esophagitisinducing drugs associated with anatomical changes of the digestive system. In the present study, contrast radiographic study was performed by inserting a catheter into the duodenum. The catheter was advanced into the pylorus, avoiding its contact with the stomach. A proximal and a distal fixation of the catheter were performed to prevent contrast reflux into the duodenum and to fix the catheter, respectively. The amount of contrast (diluted) used in the study was enough to cause gastric distension, to test the GEJ for functionality and to allow contrast flow by spontaneous and gravitational drip, after being inserted in the duodenum. The 1:1 dilution enabled a good radiographic pattern. The objective of this study was to prevent pressure exerted on the piston of the syringe to interfere with the results. The disadvantage of the Helsingen's ${ }^{7}$ model developed in rats, compared with the present experiment, was that the contrast flow was close to the esophagus because of the esophagojejunal and esophagoduodenal anastomoses performed. Another disadvantage observed in Helsingen's ${ }^{7}$ experiment was the insertion of contrast using injection. The present experiment sought to reproduce one of the causes of gastroesophageal reflux, by interfering with the cardia. The study enabled a long-term evaluation of GER. Ferguson ${ }^{19}$ developed a model in rats and other animal species, by occluding the duodenum below the pylorus, and associating with the administration of histamine. Nakamura et al. ${ }^{5}$, Inatomi ${ }^{6}$ and Omura ${ }^{4}$ developed experimental models of acid and chronic reflux esophagitis by occluding the rumen and obstructing the pylorus. The model developed by Nakamura et al. ${ }^{5}$ had the disadvantage of causing extrinsic (mechanical) gastric obstruction. Several factors will interfere with the analysis of esophagitis as a cause of reflux due to vascular compression associated with bacteria proliferation, resulting from gastric obstruction. Another factor is of gastric juice retention, which usually does not occur. The obstruction of the stomach occurring in the models mentioned above impairs the performance of the surgical technique (if used). The second disadvantage in Nakamura et al. ${ }^{5}$ model was the short survival of animals, thus being hardly applicable, since it caused acute esophagitis in too short a time to allow evaluation of therapeutic effect of the drugs tested. In the study published by $\mathrm{Melo}^{22}$, the rats underwent cardioplasty and esophagoduodenostomy. The objective was to induce carcinogenesis in the esophagus using drugs. Radiographic study was not performed in this experiment, which hinders confirming the occurrence of GER in the group of animals undergoing cardioplasty. Esophagitis was detected in 5.5\% of animals in this group. A difference was observed when different experimental models causing esophageal reflux in animals were analyzed. In the models changing the anatomy of the digestive system, significant histological changes occurred. These experiments used the models of 
anastomoses of digestive system organs. Histological changes, however, were not as intense when the technique used preserved the anatomy of the digestive system. Myectomy in the abdominal esophagus was an example of an experimental model causing esophageal reflux without resulting in esophagitis. Some models of esophageal reflux developed in animals did not present with esophagitis. ${ }^{18}$ Authors developed experimental models in dogs and the results were contradictory in relation to the cause of the esophagitis ${ }^{19,23,24}$. Smiddy and Atkinson ${ }^{18}$ developed a model in dogs, distributed into three groups: cardiomyotomy; section of the oblique gastric fibers; section of the diaphragmatic crura. The absence of esophagitis was surprising, however this does not mean that reflux did not occur. The author concludes that neither cardiomyotomy nor diaphragm section, to the left, facilitated reflux into the cardia. Carveth et al. ${ }^{25}$ performed myectomy, vagotomy and phrenicotomy in different groups of animals and concluded that cervical vagotomy caused the major alterations in the cardia. Histologic study was not carried out. The present study has the following advantages: less infrastructure is required and, probably, shorter surgical time, so that several animals may undergo surgery in the same period; intraperitoneal anesthesia was used, unlike general anesthesia in female monkeys and dogs; the animal's anesthetic recovery, postoperative feeding and weight measurement allow easier handling during these phases; venous puncture or dissection are not necessary, which makes it is easier to care for these animals, and supports the recommendation of this model; the access to animals was easier, and rat reproduction is faster when compared to that of large size animals; the lifespan of a rat is satisfactory to fit the duration of the research; with a lower morbidity and mortality, the number of deaths among the animals also decreased, which prevented delays in the research; radiographic study in small size animals may be performed without orotracheal intubation during anesthesia, thus avoiding interference of pressure exerted by mechanical ventilation in the results. The mortality rate in this experiment was $10 \%$ and occurred in the group submitted to total myectomy. It was associated to aspiration pneumonia. Because this experimental model was different from the other models described in the literature, we sought to replace the dead animals in this group to obtain a more representative number and perform a better evaluation of the results of the technique proposed. Animal deaths were $13 \%$ in a study in rats $^{12}$. Mortality due to rumen and/or esophagus perforation was $20 \%$ of the total number of animals in Nakamura's ${ }^{5}$ experiment. In a study published by Omura et al. ${ }^{4}$, mortality rate ranged from $0 \%$ to $50 \%$ in the groups studied. The risk of infection increased in the models mentioned above (abscess in anastomosis, mediastinal abscess), especially in the presence of esophageal perforation, thus increasing the number of deaths among the animals studied. In the present study, a significant weight loss in the group of rats undergoing total myectomy (80\%) was observed. We found this was associated with feed regurgitation. In this group, one animal presented with a 107-g weight loss in relation to its initial weight. The statistical analysis did not show a significant difference in weight loss between the three groups. Despite the statistical analysis results, this model caused a weight loss in $80 \%$ in group A animals, which shows that the technique used in this experiment interfered with the nutritional status of the rats. In two studies published, Helsingen ${ }^{7,10}$ observed that all rats distributed in different groups lost weight. The rats regained weight two weeks later. However, in this experiment, we did not observe weight regain in these animals. In the present study, the presence of barium in the esophagus occurred in $70 \%$ of rats in group A and in 35\% in group B, indicating that total myectomy was the technique that most often caused reflux. GER was probably acid (gastric) and chronic . This may be proportionally related to the larger area resected in the muscle layer of the lower third of the esophagus associated with truncal vagotomy. In Helsingen's ${ }^{7}$ experiment, the contrast injected in the intestine regurgitated into the esophagus of rats undergoing esophagojejunostomy and esophagoduodenostomy. The development of esophagitis in rats is related to several microscopic changes. Elongation of the papilla (hyperplasia) is present in the esophagitis. Hyperplasia results from increased thickness of the epithelium and increased number of keratinocytes. Hypergranulosis is a reactive process characterized by an intensification of keratinization. An elevated number of keratinocytes precedes keratinization. The presence of eosinophils in the lamina propria is included in the criteria used to diagnose esophagitis. Exocytosis means the occurrence of an intense inflammatory response and is characterized by the presence of inflammatory cells (eosinophils, lymphocytes) in the tissue. These cells are usually located inside the blood vessels. The atrophy of the muscle layer of the mucosa is demonstrated in the histological study, by decreased number of muscle fibers. As a consequence, the muscle tonus of the esophagus is decreased. These changes are associated with esophagitis in rats. In the present model, changes compatible with esophagitis occurred even in the control group. The results of the pathological study to evaluate esophagitis in rats are controversial, as demonstrated in this study and in other studies published in the literature. ${ }^{4,5}$ The present experiment proved the occurrence of barium reflux into the esophagus without esophagitis, because the objective was to develop an experimental model of reflux, and not of esophagitis. No surgical infection was observed in this study, thus, antibiotics were not necessary. The animals did not require intravenous hydration. The number of persons participating in the surgical technique was smaller, compared to the models using large and medium size animals. This was important, because it decreased the researcher dependence in relation to the need of assistance during the procedures, thus preventing delays in the research. The present experimental model is innovative, because it caused GER in small size animals preserving the anatomy of the digestive system. The model reproduced GER in a manner similar to that occurring in humans. This model may be very useful in the development of research on diagnostic and therapeutic means (new drugs and surgical techniques) for GER.

\section{Conclusion}

Total myectomy with a 1.5 -cm muscle layer resection of the abdominal esophagus in rats causes GER in the 
majority of animals, thus proving to be a good experimental model. Partial myectomy did not prove to be a good gastroesophageal reflux model in rats.

\section{References}

1. Zilberstein B, Ramos AC, Sallet JÁ, Engel FC, Tanikawa DYS. Esofagogastrofundoplicatura videolaparoscópica por técnica mista. Rev Col Bras Cir. 1999;26:341-5.

2. Stein HJ, DeMeester TR, Barlow, AP. Complications of gastroesophageal reflux disease. Role of the lower esophageal sphincter, esophageal acid and acid/alkaline exposure, and duodenogastric reflux. Ann Surg. 1992; 216:35-43.

3. Funes HLX, Anai GK, Santos MCL, Leite, APM, Salvador FB. Vídeo-laparoscopia no tratamento da doença por refluxo gastroesofágico. Rev Col Bras Cir. 2000;27:312-5.

4. Omura N, Kashiwagi H, Chen G, Suzuki Y, Yano F, Aoki T. Establishment of surgically induced chronic acid reflux esophagitis in rats. Scand J Gastroenterol. 1999;34:948-53.

5. Nakamura K, Ozawa Y, Furuta Y, Miyazaki H. Effects of Sodium Polyacrylate (PANa) on acute esophagitis by gastric juice in rats. Jpn J Med Sci Pharmacol. 1982;32:445-56.

6. Inatomi N, Nagaya $H$, Takami K, Shino A, Satoh $H$. Effects of a proton pump inhibitor, AG - 1749 (Lansoprazole), on reflux esophagitis and experimental ulcers in rats. Jpn J Med Sci Pharmacol. 1991;55:437-51.

7. Helsingen N. Oesophageal lesions following total gastrectomy in rats. I. Development and nature. Acta Chir Scand. 1959/1960;118:202-16.

8. Crema, E. Análise comparativa entre três tipos de válvula anti-refluxo: Anterior, posterior e lateral após a cardiomiotomia ampla: estudo experimental em cães [Tese]. São Paulo: Faculdade de Medicina de Ribeirão Preto da Universidade de São Paulo; 1998.

9. Salmon R, Hem B. Bile reflux esophagitis: a critical study of two models in the rat. Digestion. 1981;22:73-9.

10. Helsingen, N. Oesophagitis following total gastrectomy in rats. II. Development of oesophagitis in relation to type of reconstruction. Acta Chir Scand. 1960;119:230-45.

11. Kobori O, Seto Y. Role of reflux oesophagitis and acid in the development of columnar epithelium in the rat oesophagus. Br J Surg. 1993;80:467-70.

12. Levrat M, Lambert R, Kirshbaum G. Esophagitis produced by reflux of duodenal contents in rats. Am J Dig Dis. 1962;7:564-73.
13. Lambert R. Relative importance of biliary and pancreatic secretions in the genesis of esophagitis in rats. Am J Dig Dis. 1962;7:1026-33.

14. Ishii Y, Fujii Y, Yasmashita T. Effect of sodium polyacrylate on chronic reflux esophagitis in rats. Arzneim.-Forsch Drug Res. 1981;31:2112-5.

15. Mud HJ, Kranendonk SE, Obertop H, Van Houten, H, Westbroek DL. Active trypsin and reflux oesophagitis: an experimental study in rats. Br J Surg. 1982;69:269-72.

16. Pêra M, Grande L, Gelabert M, Figueras X, Pera M, Palacin A, Elena M, Cardesa A, Tiburcio AF, Trastek VF. Epithelial cell hyperproliferation after biliopancreatic reflux into the esophagus of rats. Ann Thorac Surg. 1998;65:779-86.

17. Karas LM, Stern H, Bloom D, Binder HJ, Poindexter R, Thayer W, Spiro HM. The gastroesophageal junction in the monkey and its relation to reflux. J Surg Res. 1966;6:469-77.

18. Smiddy FG, Atkinson M. Mechanisms preventing gastro-oesophageal reflux in the dog. Br J Surg. 1960;47:680-7.

19. Ferguson DJ, Sanchez-Palomela E, Sako Y, Clatworthy HW, Toon, RW, Wangensteen OH. Studies on experimental esophagitis. Surgery. 1950; 28:1022-39.

20. Selye $H$. The experimental production of peptic haemorragic oesophagitis. Can Med Assoc J. 1938;39:447-8.

21. Itoo F. Study on pathogenesis of esophagitis (part 2). Experimental esophagitis in pylorus-ligated rats(shay); morphological aspects and correlation with the volume and acidity of gastric juice. Japan J Gastroenterol.1968;65:51-7.

22. Melo LL, Kruel CD, Kliemann LM, Cavazzola LT, Boeno RD, Silber PC, Grossi RS. Influence of surgically induced gastric and gastroduodenal content reflux on esophageal carcinogenesis: experimental model in Wistar female rats. Dis esophagus. 1999;12:106-15.

23. Hwang K, Essex HE, Mann FC. A study of certain problems resulting from vagotomy in dogs with special reference to emesis. Am J Physiol. 1947;149:429-48.

24. Cross FS, Wangensteen OH. Role of bile and pancreatic juice in production of esophageal erosions and anemia. Proc Soc Exper Biol Med. 1951;77:862-66.

25. Carveth, SW. Schlegel JF, Code CF, Ellis FH. Esophageal motility after vagotomy, phrenicotomy, myotomy, and myomectomy in dogs. Surg Gynecol Obstet. 1962;114:31-42.

\section{Correspondence:}

Edmilson Vieira Gaia Filho

Av. Dr. Antônio Gouveia, 1021/801

57030-170 Maceió - AL Brazil

Phone: (55 82)3231-5730 / 9981-6390

edmilsongaia@uol.com.br
Conflict of interest: none Financial source: none

Received: May 5, 2005

Review: June 7, 2005

Accepted: July 12, 2005

\section{How to cite this article}

Gaia Filho EV, Goldenberg A, Costa HO. Experimental model of gastroesophageal reflux in rats. Acta Cir Bras. [serial on the Internet] 2005 Nov-Dec;20(6). Available from URL: http://www.scielo.br/acb

*Color figures available from www.scielo.br/acb 